\title{
Special issue on digital products
}

\author{
Kemal Altinkemer
}

Published online: 20 May 2009

(C) Springer-Verlag 2009

In this special issue of the Information Systems and e-Business Management (ISeB) we address the topic of "Digital Products". The three papers encompass the areas of IT, MIS, Marketing, and Strategy, which is becoming more and more necessary to tackle interdisciplinary issues that occur in electronic commerce such as bundling, sampling on digital music, and affiliate marketing. These papers use the interdisciplinary tools of IT, MIS, Marketing and Strategy to study "Digital Products".

First, "Digital Bundling" by Akcura and Altinkemer, is a paper analyzing bundling strategies of low-marginal-cost digital goods. Zero marginal-cost firms provide all-in-one bundles as other papers in the literature also examine. When the marginal cost increases it becomes profitable to offer many bundles. Hence this paper studies the whole spectrum of bundles: from all-in-one bundles to many bundles, and highlights the criteria that leads to different kinds of bundling situations. This paper uses game theoretic approach to analyze digital bundling and involve MIS, Marketing and Strategy.

Second, "Does sampling influence customers in online retailing of digital music" $\mathrm{Hu}$, Liu, Bose, and Shen, is an empirical study investigating the effects of sampling for digital music. The paper tries to answer questions such as when an e-tailer is likely to provide sampling for digital music and under what conditions an e-tailer is better off with sampling. This paper is a good example of interdisciplinary research.

Third, "Affiliated Marketing" by Akcura, examines an interesting topic of when a web site should be sending customers to other firms' (affiliates') sites. It takes into account the cannibalization that may occur by sending the customers to the affiliates' sites. This paper uses a game theoretic framework to analyze this situation. It uses the MIS and Marketing cross section research very well.

K. Altinkemer $(\square)$

Krannert School of Management, Purdue University, West Lafayette, USA

e-mail: kemal@purdue.edu 
The all three papers encompass the areas of IT, MIS, Marketing, and Strategy, which is becoming more and more necessary to tackle interdisciplinary issues that occur in electronic commerce. 